OPEN ACCESS

Edited by: Deseada Parejo,

Universidad de Extremadura, Spain

Reviewed by:

Ximena J. Nelson,

University of Canterbury, New Zealand Christine Renee Dahlin, University of Pittsburgh at Johnstown

USA

*Correspondence:

Karan J. Odom

kodom1@umbc.edu

Specialty section:

This article was submitted to Behavioral and Evolutionary Ecology,

a section of the journal

Frontiers in Ecology and Evolution

Received: 16 November 2015 Accepted: 09 February 2016

Published: 25 February 2016

Citation: Odom KJ, Omland KE, McCaffrey DR, Monroe MK, Christhilf JL, Roberts NS and Logue DM (2016) Typical Males and Unconventional Females: Songs and Singing Behaviors of a Tropical, Duetting Oriole in the Breeding and Non-Breeding Season Front. Ecol. Evol. 4:14. doi: 10.3389/fevo.2016.00014

\section{Typical Males and Unconventional Females: Songs and Singing Behaviors of a Tropical, Duetting Oriole in the Breeding and Non-Breeding Season}

\author{
Karan J. Odom ${ }^{1 *}$, Kevin E. Omland ${ }^{1}$, David R. McCaffrey ${ }^{2}$, Michelle K. Monroe ${ }^{1}$, \\ Jennifer L. Christhilf ${ }^{1}$, Natalie S. Roberts ${ }^{1}$ and David M. Logue ${ }^{3}$ \\ ${ }^{1}$ Department of Biological Sciences, University of Maryland, Baltimore County, Baltimore, MD, USA, ${ }^{2}$ Department of \\ Geography, University of Lethbridge, Lethbridge, AB, Canada, ${ }^{3}$ Department of Psychology, University of Lethbridge, \\ Lethbridge, $A B$, Canada
}

Recent research emphasizes that female song is evolutionarily important, yet there are still few species for which we have quantified the similarities and differences between male and female song. Comparing song rates and the structure of female and male song is an important first step to forming hypotheses about functional and evolutionary differences that may exist between females and males, especially in year-round territorial species that may use their songs for breeding and non-breeding activities. We compared female and male singing rates and song structure in a tropical New World oriole, the Venezuelan troupial (Icterus icterus) during both the breeding and non-breeding season and between the dawn and day. Males sang solos at particularly high rates during the breeding season before dawn. Females, however, sang at consistent rates year-round, primarily during the day. Females answered $75 \%$ of male day songs, producing duets, whereas males answered only $42 \%$ of female songs. Duets were common year-round, but occurred more often during the non-breeding season. Structurally, female songs were higher pitched and shorter than male songs. We detected no sex differences in the number or order of syllables, however, interestingly, answers were shorter than duet initiations and solos, and, during the breeding season, songs that initiated duets were characterized by higher syllable diversity than were answers or solos. The fact that males sing more during the breeding season supports the classical hypothesis that male song is a sexually selected trait. However, our findings that females sing solos and answer the majority of male songs to create duets year-round suggests that female song may have evolved to serve multiple functions not exclusively tied to breeding.

Keywords: female song, duet, troupial, Icterus, behavior, selection 


\section{INTRODUCTION}

Most bird song research has been conducted on temperate male songbirds and supports the hypothesis that male song is shaped by sexual selection to attract mates and defend territories (Beecher and Brenowitz, 2005; Catchpole and Slater, 2008). Conversely, very little information exists on the function or even the structure of song in female songbirds (Langmore, 1998; Riebel et al., 2005). However, recent research provides evidence that female song is common and was likely ancestral in songbirds (Odom et al., 2014). Thus, to comprehensively investigate the evolution of song in songbirds, we need to study both male and female song. Comparing the structure and timing of female and male songs is a first step in understanding the selection pressures that may be acting on the songs of each sex (Hall, 2004; Dahlin and Benedict, 2014).

Female song is particularly common in the tropics and unlike in temperate regions tropical songbirds may sing throughout the breeding and non-breeding seasons (Morton, 1996; Stutchbury and Morton, 2001). While temperate male songbirds use song to gain access to mates, female animals may use elaborate traits to compete for resources that increase their survival and fecundity (Emlen and Oring, 1977; West-Eberhard, 1983). Elaborate female traits, therefore, may evolve through broader selection pressures, such as social or natural selection to compete for and maintain multi-purpose territories or non-breeding resources (Lebas, 2006; Tobias et al., 2012; Clutton-Brock and Huchard, 2013). We propose, one way to assess whether a trait has been shaped by sexual selection is to examine whether the trait is used exclusively during the breeding season. Traits that are used well outside of the breeding season may have evolved in response to social or natural selection rather than solely sexual selection (Tobias et al., 2012).

Most studies that have directly compared male and female songs have compared structural variation (Logue and Gammon, 2004; Mennill et al., 2005; Rogers, 2005; Brunton and Li, 2006; Hall, 2006; Molles et al., 2006; Dowling and Webster, 2013; Hahn et al., 2013; exceptions: Price et al., 2008; Topp and Mennill, 2008; Illes and Yunes-Jimenez, 2009). Comparing structure of male and female song has revealed interesting trends in the overall complexity or repertoire sizes of male vs. female song. This has been used to assess the relative role of sexual selection in shaping elaboration of male vs. female traits (Mennill et al., 2005; Brunton and Li, 2006). Similarly, structural similarity and sex-specific song features have been useful for evaluating sex-role similarity and individual motivation, especially in duetting species (Logue and Gammon, 2004; Rogers, 2005; Hall, 2006).

In contrast to song structure, singing behavior and song rates may be especially informative when considering the breadth of selection pressures that impact tropical species that live in the same location year-round (Price et al., 2008; Illes and YunesJimenez, 2009). Outside of the breeding season, singing is more likely to mediate competition for resources or social interactions not related to mating. Comparing male and female song rates between the breeding and non-breeding seasons is valuable for determining the relative importance of male and female songs in regulating breeding vs. non-breeding activities (Tobias et al., 2012). Two studies report female song rates that exceed male song rates (Price et al., 2008; Illes and Yunes-Jimenez, 2009). However, no studies have examined how male and female song rates vary between the breeding and non-breeding season. Here, we quantify the song rates, as well as song structure of male and female Venezuelan troupials (Icterus icterus, hereafter "troupials") in both the breeding and non-breeding seasons to provide insight about the function and selection pressures acting on male and female song.

Troupials, a New World oriole, are a sexually monochromatic, socially monogamous, tropical-breeding songbird (Jaramillo and Burke, 1999). Mated pairs maintain territories together yearround and both males and females participate in territory defense (Odom unpublished data). Territories are predominantly nonoverlapping and nest sites are solitary (Odom unpublished data; Jaramillo and Burke, 1999). No prior studies have been conducted on banded populations of troupials and there is no formal description of their vocalizations. Previous accounts describe troupial songs as comprising 2-3 repeated, alternating low and high "whistles" (pure tones) with distinct space between notes (Jaramillo and Burke, 1999). Both males and females sing solos and mated pairs often overlap each other's songs to form duets (Odom, pers. obs.). Existing accounts also mention high rates of singing at dawn, but suggest that males are the primary singers (although others have not had banded populations; Jaramillo and Burke, 1999). Sex-specific seasonal variation in dawn singing has not been documented in tropical songbirds where female song is common. Therefore, we were also interested to quantitatively compare troupial songs and song rates between the dawn and day. Troupials are native to NE Colombia, most of Venezuela, Aruba, Curacao, and Isla Margarita, but are considered introduced to islands throughout the Caribbean including Puerto Rico, St. Thomas, the U.S. Virgin Islands, and Bonaire (Raffaele et al., 1989; Jaramillo and Burke, 1999).

We offer the first comprehensive description of variation in male and female troupial songs (Figure 1). Our paper has two goals: (1) quantify the singing behavior and song structure variation in male and female troupials, and (2) determine whether male and female singing behavior and song structure varies as a function of season (breeding vs. non-breeding) or time of day (dawn vs. day). We discuss our results in the context of existing information on the function and selection pressures acting on male and female songs and duets.

\section{Methods}

We collected data over three field seasons in the dry forests of Cabo Rojo National Wildlife Refuge in southwestern Puerto Rico $\left(17^{\circ} 590 \mathrm{~N}, 67^{\circ} 100 \mathrm{~W}\right)$, constituting two breeding seasons and one non-breeding season. We recorded Troupials from 10 May to 30 June 2013, 22 April to 01 July 2014, and 09 November to 18 December 2014. Late April to early May is the beginning of the wet season in Puerto Rico and the start of the breeding season for troupials in the dry forests of the island. October to April is the dry season, which is the non-breeding season for troupials in our study area. Our non-breeding season research was conducted in the first half of the non-breeding season, and thereby avoiding any confounding effects of pre-breeding activities. 


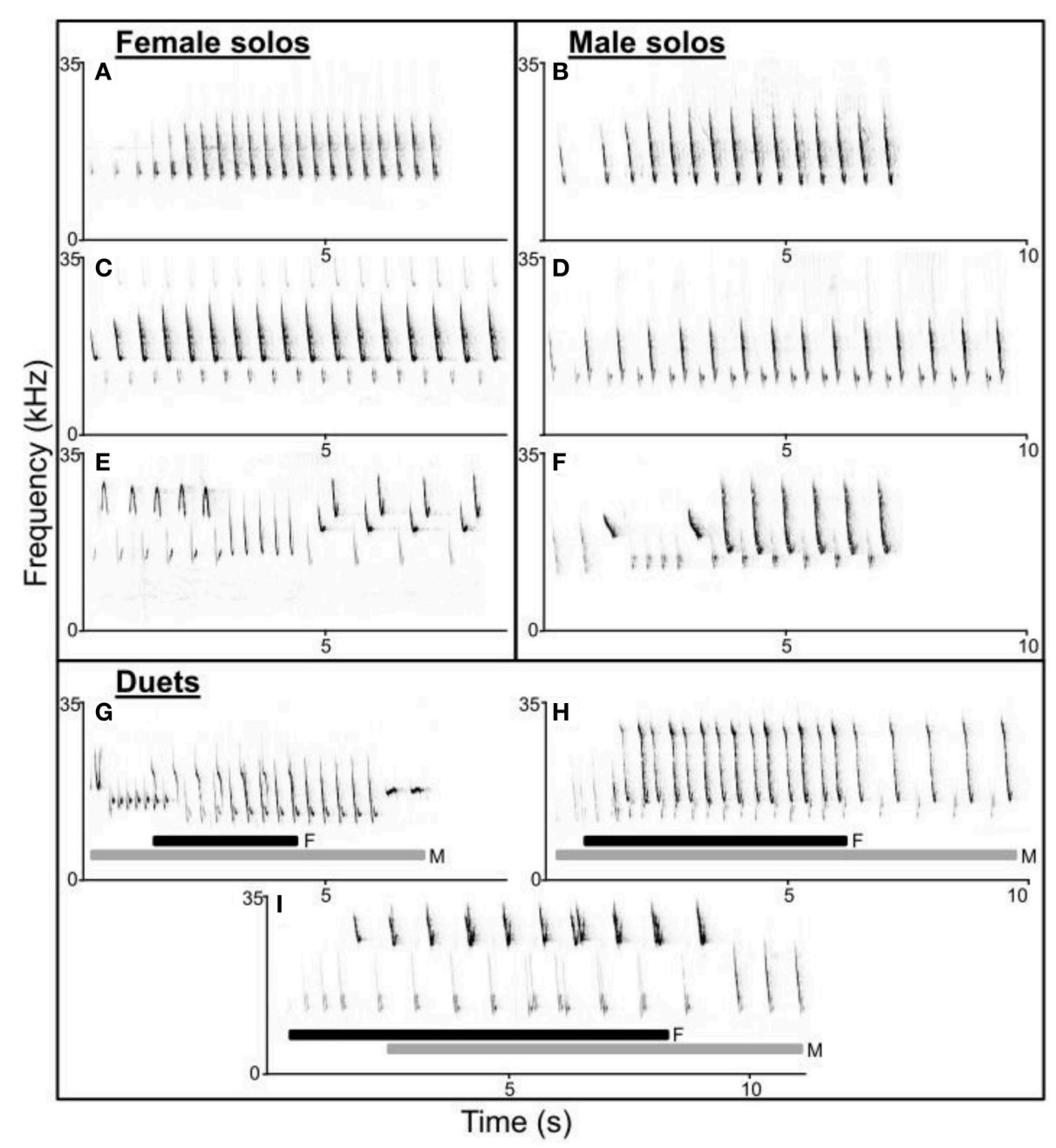

FIGURE 1 | Spectrograms of troupial (Icterus icterus) female (A,C,E) and male (B,D,F) solos and duets (G-I). Female and male songs have similar structure (A-D) and range from 1 to 3 alternating syllables most often used in repeating motifs. Both female and male songs can have simple $(\mathbf{A}, \mathbf{B})$ or complex $(\mathbf{E}, \mathbf{F})$ syllable diversity and order. Duets vary structurally including both male-initiated $(\mathbf{G}, \mathbf{H}$; female part of duet underlined by black bars) and female-initiated (I; male part underlined by gray bars) duets. In addition, both songs and syllables within duets may overlap to varying extents and troupials may use different $\mathbf{( G )}$ or similar $(\mathbf{H}, \mathbf{I})$ song types as their mate within duets.

For this study, we focused only on mated, territorial pairs of troupials. Over the three field seasons, we regularly recorded 16 pairs of troupials. Turnover in mates and territories resulted in a final sample size of 19 males and 18 females (see Supplementary Table 1 for a full list of sample sizes and number of songs included in each analysis). All troupials were banded with individual and sex-specific celluloid color bands and a USGS aluminum band. Males were fitted with an aluminum band over a light blue band on their left leg whereas females received a light pink over aluminum band on their right leg. Troupials are sexually monochromatic to human observers, so the colored leg bands allowed us to identify sexes in the field. Sex was tentatively assigned in the field by wing length measurements. Males on average have a wing length of $118.9 \mathrm{~mm}( \pm 3.3 \mathrm{~mm}$ SD) while female wing lengths average $110.9 \mathrm{~mm}( \pm 2.4 \mathrm{~mm}$ $\mathrm{SD})$. In the field, sex identification was aided by the presence of a brood-patch or cloacal protuberance during banding, and breeding activity afterward (e.g., female nest building and incubation). We confirmed sex of our mated pairs using molecular sexing in the lab (Griffiths et al., 1998). In the summer and fall 2014, each male and female of our mated pairs were fitted with a very high frequency (VHF) radio tag to further aid in quick identification and location of individuals (radio transmitter models Pip Ag386 and Ag393 manufactured by Biotrack). We recorded birds with a Marantz PMD 661 recorder and Sennheiser ME67 shotgun microphone with K6 power module. All field methods and protocols were approved by the University of Maryland, Baltimore County IACUC committee (approval number KO010531215) and we had all necessary federal and state permitting (Federal bird banding permit number 23205 and Puerto Rico Department of Natural Resources scientific permit number R-VS-PVS15-SJ-00423-09102014). 
We recorded birds during standardized 1-h observation sessions. We conducted three sessions within the first $4 \mathrm{~h}$ after sunrise each morning (allowing time between sessions to locate and identify pair members before the start of each observation). We cycled through each pair of troupials before re-observing a pair so that all pairs were regularly observed at least once per week. Each pair was also observed an equal number of times each hour of the morning relative to sunrise. During observations, we recorded and noted male solos, female solos, and duets that occurred within each observation session, as well as which sex sang first or second in the duet when we saw who sang which part of the duet. We defined duets by the presence of temporally overlapping song. We also noted when one or both pair members were not present and adjusted song rates to reflect the proportion of the time birds were present. We did not include songs in the analysis that were given when we did not know the location of at least one pair member or when we were uncertain which bird vocalized. All observations were conducted by two observers so that each observer could focus on watching one member of the pair.

All pairs were recorded at least once at dawn during both the breeding and non-breeding seasons of 2014 (the two seasons we had radio tags). We began dawn recordings approximately 45 min before sunrise and continued recording until the sun was visible on the horizon or the pair left the area (whichever happened first). We used radio tracking to identify and verify the location of each pair member before we began recording. We tracked individuals to within $20-30 \mathrm{~m}$ of roosting locations to be confident in each bird's location. We only included recordings in which pair members were far enough away from one another that their radio signals and, therefore, their vocalizations could be separated spatially and the expected locations of individuals based on radio tracking matched the location of vocalizing troupials.

We measured several components of troupial songs, including song rate, frequency, duration, and song syllable composition. Songs for fine-structural measurements and composition were extracted from the full dawn and day time recordings, as well as a few recordings made prior to playback experiments. For frequency measurements, we only included recordings with a strong signal, low noise, and no loud sounds obstructing the song. For temporal measurements and composition, we used only songs for which we could clearly see the beginning and end of the song, as well as the component syllables. There were some songs that we measured for composition but not temporal measurements because syllables could be identified but not measured, or vice versa.

\section{Song Rate}

Song rate was calculated for male solos, female solos, and duets within each recording. Daytime song rates were calculated by dividing the number of each vocalization type by the time that one or both pair members were present during an observation session. For dawn songs, we divided the overall number of each vocalization type by the duration of the recording (equivalent to the time we spent in close radio contact with a pair). Ideally, this overall comparison of solo and duet rates would have included the component male and female initiation and answer rates, allowing us to fully reconstruct the individual-level behaviors of males and females. However, we only observed which individual initiated or answered duets in $48 \%$ of duets (largely because troupials often fly or are engaged in territorial interactions right before duetting). Therefore, we used the percent of female and male day time solo and duet rates from the above analysis and known duet initiation rates to calculate the percent of male and female total initiations (solos plus songs used to initiate duets) and answers (songs used to respond to a mate's song to form a duet). In other words, we calculated overall initiation and answer rates from the component percentages of solo and duet initiation rates (see Table 2). We only used 2014 data for song rate analyses because we only had dawn singing rates for 2014. We only used daytime singing rates for initiation rate calculations because very few duets or female solos are produced at dawn.

\section{Structure}

All fine-structural measurements were completed in RavenPro v1.4 (Bioacoustics Research Program, 2011).

\section{Frequency Measurements}

We used RavenPro's automated measurements to provide standardized measures of frequency based on the energy of the signal rather than the spectrogram itself, including $95 \%$ frequency (upper frequency), 5\% frequency (lower frequency), and $90 \%$ frequency bandwidth (Bioacoustics Research Program, 2011; Zollinger et al., 2012). We measured these parameters for male and female solo songs; substantial overlap of syllables within duets prevented accurate frequency measurements for duet initiations and answers. Frequency measurements were conducted using the Hann window function and transform size 1024 points for an effective frequency resolution of $5.8 \mathrm{~Hz}$. We also measured peak frequency (the frequency at peak amplitude), however, peak frequency was highly correlated with all other frequency measures, so we only include analyses of the previous three frequency measures.

\section{Temporal Measurements}

We measured total duration of male and female solo songs as well as the component male and female songs from within duets. For temporal measurements, we used a transform size of 256 points and we viewed only $4 \mathrm{~s}$ of each song at a $100 \%$ window width for an effective time resolution of $0.003 \mathrm{~s}$. We used the end time subtracted from the begin time of a selection encompassing the entire song to calculate total duration of each song. We estimated the beginning and end time of each song on the spectrogram, but compared the spectrogram to the waveform while making our measurements to increase our ability to precisely determine where the first syllable began and last syllable ended.

\section{Syllable Composition}

Male and female solo songs, duet initiations, and answers were measured for composition analyses. Syllables were separated into discrete syllable types based on overall shape and frequency range. Each syllable type was assigned a distinct letter code and a graph network-based approach was used, wherein 
nodes represent syllable type letter codes, and edges represent transitions between syllables (Sasahara et al., 2012). Four aspects of song composition were quantified: (1) number of syllables per song, (2) syllable diversity (number of syllable types per syllable), (3) number of transitions between syllable types, and (4) the average minimum path length between all pairs of syllable types in the graph network. We did not convert transitions to a rate because doing so resulted in non-normally distributed principal components. Average minimum path length (hereafter "path length") is a graph network metric that measures the average minimum distance between nodes (i.e., pairs of syllables). Path length quantifies an aspect of syntactical orderliness, with longer paths indicating greater order (Sasahara et al., 2012). Average minimum path length was calculated in $\mathrm{R}$ using the igraph package (Csardi and Nepusz, 2006; R Core Team, 2015). We used principal components analysis (PCA) to reduce the number of variables and account for correlation among variables. We did not employ rotation because the unrotated solution was satisfactory, and rotation can complicate interpretation of components (Jolliffe, 2002). Bartlett's test of sphericity indicated that data were suitable for PCA $\left(\chi^{2}=1852.18, d f=6, p<\right.$ 0.0001 ). A scree plot was used to determine the number of principal components for analysis.

\section{Statistical Analysis}

All statistical analyses were performed in R (R Core Team, 2015), except PCA of the composition data, which was conducted in InfoStat v 2012 (Di-Rienzo et al., 2012). Separate analyses were conducted for song rate, frequency, duration, and syllable composition. Song rates were analyzed using non-parametric Kruskal-Wallis analyses. We used non-parametric analyses for song rate because the data were continuous and zero-inflated. We conducted separate, individual tests to compare song rate to the fixed effects of song type (male solo, female solo, or duet), time of day, and season and their two-way interactions. To control for multiple recordings per bird, we averaged song rate by individual and pooled the averages according to song type, time of day, and season for each analysis. We assessed variation in answer rates attributable to sex and season with a generalized linear mixed model (GLMM) of answer rates with fixed effects sex, season, and their interaction, and random effects individual and year using the "Ime4" package in R (Bates et al., 2015).

For frequency, duration, and syllable composition analyses we built linear mixed models (LMM) using the "Ime4" package in R (Bates et al., 2015). For these analyses, we included sex and season as fixed effects and individual and year as random effects. Frequency analyses only included songs produced as solos, whereas duration and composition analyses included male and female songs both from solo songs as well as the component male and female songs within duets. Therefore, duration and composition analyses included an additional fixed effect of role, which accounted for whether a song was a solo, a duet initiation (the first song sung in a duet), or an answer (the second bird to sing in a duet). Time of day was included as a single fixed effect in a separate LMM than sex, season, and role because we only had enough measureable dawn songs for males during the breeding season. Female songs were too infrequent at dawn to have a large enough sample size for statistical analysis. Therefore analyses with sex, season, and role were restricted to songs sung during the day, whereas analyses including time of day included only males in the breeding season. Analyses with sex, season, and role also included the two-way interaction terms of sex*season, sex*role, and season*role. We dropped interaction terms that did not contribute to a significant portion of the variation in the full model, assessed by backward selection, resulting in a reduced model. To assess significance of main fixed effects and any remaining interactions, we pairwise compared the reduced model to drop-one models containing all remaining fixed effects except the one being assessed. We compared each drop-one model to the full model using an ANOVA F-statistic to produce $p$-values. We accepted an alpha-level of $p=0.05$ as statistically significant for all analyses.

\section{RESULTS}

\section{Song Rate}

Song rate varied significantly depending on song type (male solo, female solo, or duet) as well as with the interaction of song type by season and song type by time of day (Table 1; Figure 2). There was no effect of season or time of day individually or the interaction of season and time of day (Table 1). These differences in song rate were driven primarily by disproportionately high rates of male solos: males sing significantly more solos than do females and most male songs are solos rather than duets (Table 1). However, variation in the rates of each song type are driven primarily by interactions with season and time of day, as follows (Table 1). Male soloing is prominent at dawn and during the breeding season. Conversely, females sing very little at dawn, but sing more solos than males in both the breeding and non-breeding season ( $29 \%$ of all day songs are female solos vs. only $12 \%$ are male solos; Tables 1, 2; Figure 2). However, during the day, most often male and female songs are answered to produce duets (Tables 1, 2; Figure 2). Duets were produced more often during the non-breeding vs. the breeding season (Table 1; Figure 2).

When we considered the individual-level behaviors of male and female initiation and answer rates, males and females initiate approximately the same number of songs during the day

TABLE 1 | Song rate analyzed for song type (male solo, female solo, or duet), season (breeding or non-breeding), time of day (dawn or day) and their interactions using a Kruskal-Wallis non-parametric analysis of individual averages.

\begin{tabular}{lllccc}
\hline Data & $\begin{array}{l}\text { Response } \\
\text { variable }\end{array}$ & Explanatory variable & $\boldsymbol{d f}$ & $\boldsymbol{x}^{\mathbf{2}}$ & $\boldsymbol{p}$-value \\
\hline All songs & Songs per hour & Song type & 2 & 12.75 & $\mathbf{0 . 0 0 2}$ \\
& & 1 & 0.01 & 0.928 \\
& & Season & 1 & 0.27 & 0.603 \\
& & Time of day & 5 & 48.17 & $<\mathbf{0 . 0 0 1}$ \\
& Season* Song type & Time of day * Song type & 5 & 27.68 & $<\mathbf{0 . 0 0 1}$ \\
& & Season*Time of day & 3 & 6.23 & 0.101 \\
\hline
\end{tabular}

Values in bold are statistically significantly different based on a p-value of 0.05 . 


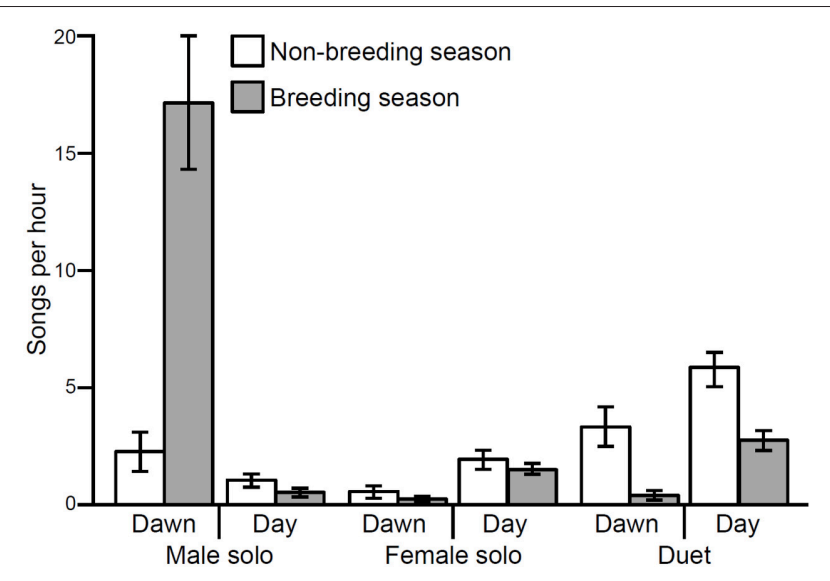

FIGURE 2 | Song rates (per hour) for troupial male solos, female solos, and duets vary significantly from one another $\left(X^{2}=12.75, d f=2, p<\right.$ $0.01)$ especially between the breeding and non-breeding season $\left(X^{2}=\right.$ 27.68, $d f=5, p<0.01)$ and dawn vs. day $\left(X^{2}=48.17, d f=5, p<0.01\right)$. Bars represent means with standard error bars.

TABLE 2 | Sex-specific rates of solo singing, initiation, and duet answers show that males and females initiate about the same number of songs but females answer male songs to form duets at much higher rates than males answer female songs.

\begin{tabular}{lcccc}
\hline Sex & $\begin{array}{c}\text { Solos } \\
\text { (out of all } \\
\text { songs) } \%\end{array}$ & $\begin{array}{c}\text { Duet initiations } \\
\text { (out of all } \\
\text { songs) } \%\end{array}$ & $\begin{array}{c}\text { Total initiations } \\
\text { (solos + duet } \\
\text { initiations) } \%\end{array}$ & Answers \\
\hline Male & 12 & 37 & 49 & 42 \\
Female & 29 & 21 & 51 & 75 \\
\hline
\end{tabular}

(including solos and duet initiations; Table 2). Females answer $75 \%$ of male songs (Table 2). Males, however, answer only $42 \%$ of female songs (Table 2). These values account for the lower rates of male solo singing during the day: females answer a majority of male songs, turning them into duets. Females therefore answer a significantly larger portion of duets (GLMM: sex: $X^{2}=9.14, d f=$ $1, p<0.01)$. Answering rates do not vary with season (GLMM: season: $X^{2}=0.01, d f=1, p=0.92$ ).

\section{Structure}

Troupial solos and duets varied considerably in structure and composition (Figure 1). In our population, most male and female songs consisted of 1-3 alternating syllables used in repeated motifs (Figure 1). However, while we noticed that individual troupials appear to have repertoires of a few song types (approximately 2-4 song types each for both males and females), song types are not entirely stereotyped. Both male and female troupials may substitute notes from one song with similarly structured notes from another song, or alternate among motifs after variable numbers of phrase repetitions, creating more complex song types (Figures 1E,F). The timing and extent of overlap and the song types used in duets also varies widely (Figures 1G-I). While simple song types were shared by many individuals in the population, complex song types appeared to
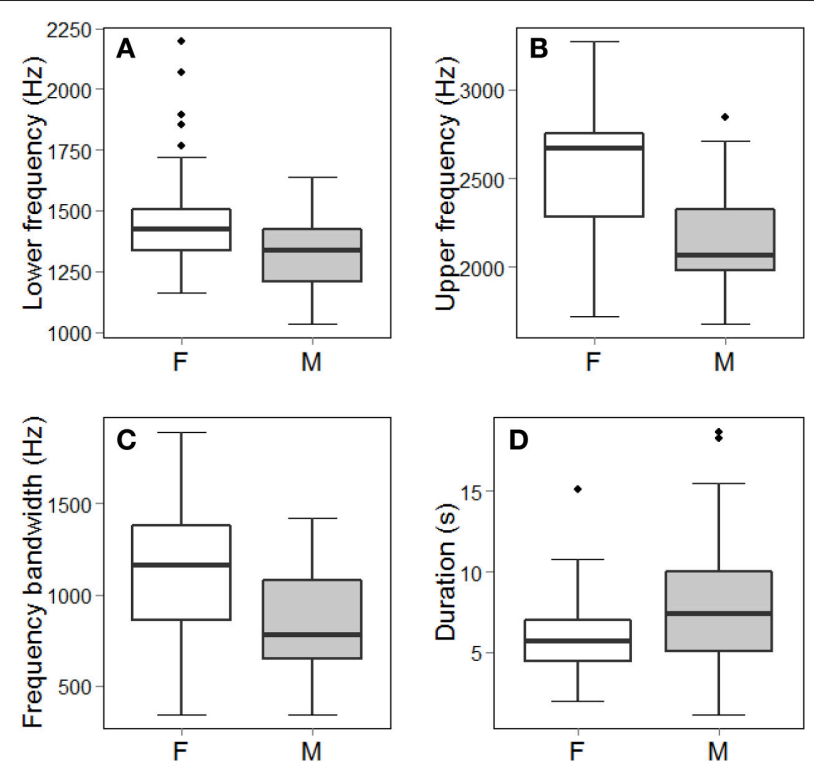

FIGURE 3 | Frequency (A-C) and temporal (D) measurements that were statistically significantly different between female $(F)$ and male (M) song ( $\boldsymbol{p}<\mathbf{0 . 0 1}$; see Table 4). Note, however, the broad range overlap for all four parameters. Box and whisker plots show the entire distribution of the data, including median, 1st and 3rd quartiles, all data within 1.5 times the Inter Quartile Range beyond the 1st and 3rd quartiles, and outliers.

be shared among fewer individuals. Although, syllables used to create most song types were widely shared within the population.

\section{Frequency Measurements}

Female songs were characterized by significantly higher upper and lower frequencies and larger frequency bandwidths than were male songs (Table 4; Figure 3). There was, however, substantial frequency overlap between male and female song (Figure 3). Frequency measurements of male and female songs did not differ between seasons (Table 4). Upper frequencies and frequency bandwidth did not vary between male dawn and day songs (Table 4). The lower frequencies of male dawn songs, however, were marginally significantly higher than those of male day songs (Table 4). Interaction terms did not contribute to a significant amount of variation (Lower frequency Sex* Season: $X^{2}=0.004, d f=1, p=0.94$; Upper frequency Sex*Season: $X^{2}=$ $1.39, d f=1, p=0.24$; Frequency bandwidth Sex* Season: $X^{2}=$ $1.31, d f=1, p=0.25$ ).

\section{Temporal Measurements}

For temporal measurements, there were significant effects of sex, season, role, and time of day (Table 4). Males produced significantly longer songs than females (Figure 3; Table 4). However, the range of female song durations falls entirely within the range of male song durations (Figure 3). Songs sung during the breeding season are shorter than songs sung in the non-breeding season (Table 4). Songs used as answers are significantly shorter than duet initiations (Table 4), but neither duet initiations nor answers were significantly different from solo 
songs (Tukey's post-hoc test of LS means: answerer-initiator: $t$ ratio $=2.85, d f=461, p=0.01$; solo-initiator: $t$-ratio $=0.95$, $d f=458, p=0.61$; solo-answerer: $t$-ratio $=-2.11, d f=467, p=$ $0.09)$. Lastly, male dawn solos were significantly longer than male daytime solos (Table 4). Interaction terms did not contribute to a significant amount of variation (Sex*Season: $X^{2}=3.05, d f=$ $1, p=0.08$; Sex Role: $X^{2}=1.94, d f=2, p=0.38$; Season* Role: $\left.X^{2}=1.52, d f=2, p=0.47\right)$.

\section{Syllable Composition}

Scree plot analysis indicated that the first two principle components were appropriate for analysis (eigenvalues $=2.04$ and 1.57). Together, they explain $90 \%$ of the variation $(\mathrm{PC} 1=$ $51 \%$ and $\mathrm{PC} 2=39 \%$ ) in the composition variables. High values of PC1 characterize songs with many syllables and many transitions between syllable types (Table 3). High values of PC2 characterize songs with many syllable types arranged in an orderly syntax.

The composition of songs sung during the day (both within duets and as solos) did not differ by sex (Table 4). The significant effect of season on PC1 indicates that non-breeding season songs were longer and contained more transitions than did breeding season songs. Answers were characterized by fewer syllables and transitions than either solos or initiations, but solos and initiations were statistically indistinguishable (Tukey's post-hoc test of LS means: answer vs. initiation: $t$-ratio $=-3.90, d f=614$, $p=0.0003$; answer vs. solo: $t$-ratio $=-4.06, d f=613, p=0.0002$; initiation vs. solo: $t$-ratio $=0.23, d f=606, p=0.97$ ).

There was a significant role-by-season interaction in the PC2 model. Examination of the interaction plot revealed that between-season changes in initiations were the primary driver of this interaction (Figure 4). Specifically, initiations had higher syllable type diversity and path lengths in the breeding season than they did in the non-breeding season (initiation breeding vs. initiation non-breeding: $t$-ratio $=-3.58, d f=253, p=0.0055$ ). The only statistically significant role-by-season comparison that did not involve breeding season initiations indicated that breeding season answers had lower values of PC2 than did breeding season solos $(t$-ratio $=-3.01, d f=601, p=0.033)$.

We did not detect significant compositional differences between male songs that were sung before dawn, vs. those sung during the day (Table 4). The residuals of LMMs for all structural analyses were approximately normal and homoskedastic.

\section{DISCUSSION}

Troupials have notable sex differences in their singing behavior. Males sing most during the breeding season at dawn, whereas

TABLE 3 | Principle Component Analysis (PCA) loading values for troupial song composition data.

\begin{tabular}{lrr}
\hline Variable & PC1 & PC2 \\
\hline Number of syllables & 0.65 & -0.17 \\
Syllable diversity & -0.21 & 0.74 \\
Number of transitions & 0.64 & 0.05 \\
Path length & 0.35 & 0.65
\end{tabular}

females sing consistently year-round during the day. Similar to female songs, duets are produced year-round, but duets occur at higher rates during the non-breeding season. Females appear to play a large role in shaping daytime vocal behavior: females and males initiate similar numbers of day songs, but females answer a majority of male songs to create duets. Male and female troupial songs exhibit some differences in frequency and duration, but have similar syllable composition. These results suggest male and female song structure is under similar selection pressures, but that the selection pressures influencing male and female singing behavior varies. While key aspects of male singing behavior seem to be under classical breeding season pressures, female singing behavior may be influenced by a range of selection pressures that likely includes sexual as well as broader social or natural selection pressures.

\section{Song and Duet Rates and Selection Pressures}

The year-round occurrence of duets but increased rate in the non-breeding season suggests that song answering likely functions in resource defense (Hall, 2004). Troupials eat fruits and insects, resources that may be particularly limited during the dry, non-breeding season (Skutch, 1996; Jaramillo and Burke, 1999). To defend an area suitable to encompass sufficient amounts of these resources may require increased territory defense in the non-breeding season. In addition, the nonbreeding season may be a time of year when hatch-year birds are dispersing and attempting to establish territories. Increased territory defense may be required at this time of year to deter dispersing birds from foraging or settling within inhabited territories.

We were surprised to find that female answer rates exceeded male answer rates. Sex differences in answering rates could evolve as a consequence of sex differences in the costs

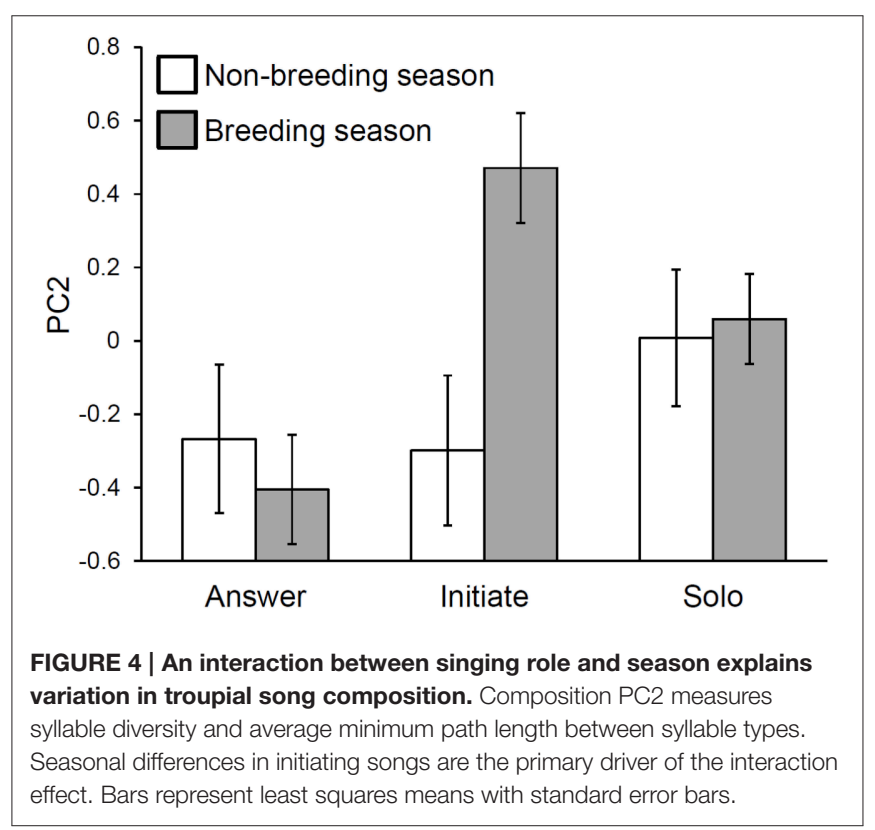




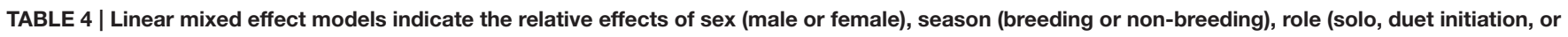
answer) and time of day (dawn or day) on structural frequency, temporal, and composition measurements of troupial songs.

\begin{tabular}{|c|c|c|c|c|c|c|c|c|}
\hline Measurement & Data & Response variable & Explanatory variable & Value & SE & $d f$ & $x^{2}$ & $p$-value \\
\hline \multirow[t]{9}{*}{ Frequency } & Male and female day solos & Lower frequency & Sex: male & -107.55 & 59.41 & 1 & 7.01 & $<0.01$ \\
\hline & & & Season: breeding & -50.48 & 31.73 & 1 & 3.16 & 0.08 \\
\hline & & Upper frequency & Sex: male & -486.21 & 112.74 & 1 & 20.87 & $<0.01$ \\
\hline & & & Season: breeding & -27.06 & 58.78 & 1 & 0.03 & 0.87 \\
\hline & & Bandwidth & Sex: male & -381.45 & 118.15 & 1 & 11.54 & $<0.01$ \\
\hline & & & Season: breeding & 24.60 & 60.86 & 1 & 1.21 & 0.27 \\
\hline & Male dawn and day solos & Lower frequency & Time of day: day & -60.51 & 30.06 & 1 & 3.87 & 0.05 \\
\hline & & Upper frequency & Time of day: day & 24.57 & 76.11 & 1 & 0.10 & 0.75 \\
\hline & & Bandwidth & Time of day: day & 80.81 & 72.48 & 1 & 1.20 & 0.27 \\
\hline \multirow[t]{6}{*}{ Temporal } & All day songs & Duration & Sex: male & 2.42 & 0.67 & 1 & 10.45 & $<0.01$ \\
\hline & & & Season: breeding & -1.27 & 0.54 & 1 & 21.90 & $<0.01$ \\
\hline & & & Role: & & & 2 & 8.72 & 0.01 \\
\hline & & & Soloist & -0.18 & 0.54 & & & \\
\hline & & & Answerer & -1.24 & 0.55 & & & \\
\hline & Male dawn and day solos & Duration & Time of day: day & -2.58 & 0.6 & 1 & 17.91 & $<0.01$ \\
\hline \multirow[t]{15}{*}{ Composition } & All day songs & PC1 & Sex: male & 0.30 & 0.23 & 1 & 1.84 & 0.18 \\
\hline & & & Season: breeding & -0.31 & 0.12 & 1 & 6.54 & 0.01 \\
\hline & & & Role: & & & 2 & 20.36 & $<0.01$ \\
\hline & & & Soloist & 0.55 & 0.14 & & & \\
\hline & & & Initiator & 0.58 & 0.15 & & & \\
\hline & & PC2 & Sex: male & 0.11 & 0.19 & 1 & 0.35 & 0.55 \\
\hline & & & Season: breeding & -0.14 & 0.20 & 3 & 16.46 & $<0.01$ \\
\hline & & & Role: & & & 4 & 27.58 & $<0.01$ \\
\hline & & & Soloist & 0.27 & 0.20 & & & \\
\hline & & & Initiator & -0.03 & 0.21 & & & \\
\hline & & & Season * Role: & & & 2 & 13.28 & $<0.01$ \\
\hline & & & Breeding - Initiator & 0.91 & 0.27 & & & \\
\hline & & & Breeding-Soloist & 0.19 & 0.25 & & & \\
\hline & Male dawn and day solos & PC1 & Time of day & 0.16 & 0.24 & 1 & 0.008 & 0.93 \\
\hline & & PC2 & Time of day & -0.16 & 0.18 & 1 & 0.75 & 0.39 \\
\hline
\end{tabular}

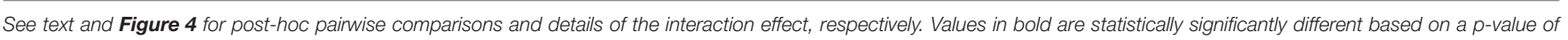
0.05 .

and benefits of song answering (Hall, 2004). Temporally overlapping answers by one sex have been cited as evidence of mate guarding by the overlapping sex (Sonnenschein and Reyer, 1983; Tobias and Seddon, 2009; Dowling and Webster, 2015). In troupials, there is no obvious reason for females to guard mates, especially during the non-breeding season, and indeed, both sexes of troupials overlap the mate when answering. Females, however, could overlap male songs in the non-breeding season to prevent usurpation of mates by advertising that their male is taken at a time when many young females may be available and establishing new territories. This presents an interesting scenario where female answering could prevent mate loss outside of the breeding season in a way that ties into pair-bond maintenance for the breeding season. However, it is important to note that our analyses were conducted on already mated pairs of troupials, so the abundance, timing, and selection pressures on singing behavior might vary among unmated individuals. Moreover, pre-breeding activities represent a time when physiological changes pertaining to breeding activity are occurring, so would be a particularly interesting time to examine sexually selected pressures on singing behaviors.

\section{Sex Differences in Song Structure}

Female troupial songs are higher pitched and shorter than male songs. Females also have a larger overall frequency bandwidth compared to males, caused by the fact that the high frequencies within female songs are disproportionately higher than their lower frequencies (Figure 3). Female songs are also shorter than male songs, yet, we did not find any differences in number of syllables or syllable composition between male and female songs, suggesting that female songs may just be faster paced. Indeed, visually, some female songs appear to have slightly shorter internote intervals than male songs. This is interesting, in the context 
of selection pressures and performance trade-offs that are known to exist between frequency bandwidth and syllable rate for certain temperate male songbirds (Podos, 1997; Podos and Nowicki, 2004; Byers et al., 2010). However, information is needed on whether females are actually singing more rapid songs than males.

The frequency and temporal differences we detected between male and female troupial songs were subtle; they would not allow for sex identification with high confidence (Figure 3). Moreover, we did not detect any differences in note composition between the sexes. Overall, troupial songs are remarkable for their relative lack of sexual dimorphism. Some species, including some monochromatic species, exhibit distinctive sex-specific songs or structural features (Mennill et al., 2005; Rogers, 2005; Logue et al., 2007). However, in other species, males and females have similar overall structure, but differ in a few, continuous parameters, such as frequency or number of syllables (Mennill et al., 2005; Brunton and Li, 2006; Illes and Yunes-Jimenez, 2009). Some of these species have fairly substantial differences in pitch or syllable number that even allows researchers to distinguish among males and females (Mennill et al., 2005). In still other species, males and females exhibit different levels of vocal complexity that may be indicative of selection for more elaborate songs in one sex over the other (Brunton and Li, 2006; Illes and Yunes-Jimenez, 2009). However, we suggest that troupials exhibit less sexually distinct songs than most previously examined species, supported by the substantial overlap of frequency and duration of their songs (Figure 3). While it is important to examine the possibility of sex differences, a lack of or reduced sexual variation may also be biologically meaningful or informative, especially in a sexually monochromatic, year-round territorial species that may share sex-roles.

\section{Differences in Song Composition between Initiators and Answers}

We observed that song structure depended on whether the song was used as a solo, to initiate a duet, or to answer within a duet. This finding emphasizes the importance of examining individuallevel analyses within duets that allow for variation among initiators and answers, in addition to sex-specific variation.

Our finding that songs sung as answers have fewer syllables and less order than solos or duet initiations complements our finding that answers are also shorter than duet initiations. We conclude that birds use short songs to answer their mates. More interestingly, during the breeding season duet initiations were characterized by substantially higher syllable diversity and syntactical structure than either solos or answers. We offer three possible explanations for this finding. First, initiators "know" they are likely to be answered and sing a specific song type. Second, initiators may begin solos and initiations the same (e.g., because they do not "know" if they will be answered), but then change them after they have been answered (Tobias and Seddon, 2009). Third, mates may preferentially answer more complex songs. Testing these alternative hypotheses by examining the fine-scale structure of initiations relative to the timing of answers would shed light on the mechanisms and functions of duet singing in this and other species that duet by overlapping the mates' songs.

\section{Seasonal and Diel Variation}

Temporal and composition analyses revealed that non-breeding season songs are longer and contain more transitions than do breeding season songs. Such seasonal variation is consistent with the general trend toward more day time song output in the nonbreeding season. This further supports the hypothesis that one function of troupial songs is to mediate competition for scarce resources in the dry season.

Overall, there was little variation in the structure of male songs between dawn and day despite greatly heightened song rates at dawn. Dawn songs were longer than day songs and had higher low frequencies. Male dawn and day songs had similar syllable composition. Since male songs are longer at dawn with little differences in syllable number or order, perhaps males sing slower at dawn. Based on visually comparing male dawn and day songs, this appears to be true for some males, but varies by song type.

\section{CONCLUSIONS}

Female vs. male singing behavior differs in ways that have interesting implications for understanding selection pressures acting on females and males. Increased male solo singing rates during the breeding season at dawn are consistent with the classical view of male song as a trait that has evolved under the influence of female choice. The use of both male and female song year-round, both as solos and duets, indicates that male and female song also serve functions that are not tightly tied to mating. The increased rate of duetting in the non-breeding season specifically supports the use of duets for year-round territory defense. The finding that female answer rates exceed male answer rates could be viewed as supporting the hypothesis that answering functions in mate guarding or it could reflect the different ways in which males and females participate in resource defense (Hall, 2004). Male and female songs were surprisingly similar in structure suggesting that sex-roles are fairly similar, as might be predicted in year-round territorial species (Stutchbury and Morton, 2001). Variation in troupial song structure based on whether a bird initiates or answers a duet indicates that troupial song composition may be more flexible than traditionally recognized, especially compared to songbird species that crystalize song early in life.

\section{AUTHOR CONTRIBUTIONS}

This research is part of dissertation research of KJO with supervision by advisor KEO and committee member DL at all stages. KJO, KEO, and DL all contributed to the conception and formation of the research ideas. Field work was predominantly carried out by KJO and MM. KJO, MM, JC, DM, NR, and DL all contributed to data collection and processing. Statistical analysis was completed by KJO, DM, and DL. The manuscript was written by KJO, DL, and KEO with contributions and comments by all authors. 


\section{ACKNOWLEDGMENTS}

The authors thank O. Diaz, G. Burgos, J. Padilla, R. Antonetti, A. Roman, and S. Silander for help coordinating field housing and field site logistics. We are grateful for dedicated field work by W. Beckles, S. Campbell, H. Hughes, K. Fleming, S. FloresLlanos, A. La Porte, O. Medina, J. Reese, D. Rodrigez, L. Rodrigez-Sanoguet, and I. Rojas-Ferrer. We also thank Frontiers in Ecology and Evolution for hosting this special issue and M. Hall and N. Langmore for the invitation to contribute. Funding for field research was provided primarily through small grants awarded to KJO by the following societies and organizations: American Museum of Natural History, American Ornithologists' Union, American Society of Naturalists, Animal Behavior Society, The Explorer's Club -Washington Group, Society for

\section{REFERENCES}

Bates, D., Maechler, M., Bolker, B., Walker, S., Christensen, R. H. B., Singmann, H., et al. (2015). Package 'Ime4'. Available online at: https://cran.r-project.org/web/ packages/lme4/lme4.pdf

Beecher, M. D., and Brenowitz, E. A. (2005). Functional aspects of song learning in songbirds. Trends Ecol. Evol. (Amst). 20, 143-149. doi: 10.1016/j.tree.2005.01.004

Bioacoustics Research Program (2011). Raven Pro: Interactive Sound Analysis Software, version 1. 3. Ithaca, NY: Cornell Laboratory of Ornithology.

Brunton, D. H., and Li, X. (2006). The song structure and seasonal patterns of vocal behavior of male and female bellbirds (Anthornis melanura). J. Ethol. 24, 17-25. doi: 10.1007/s10164-005-0155-5

Byers, J., Hebets, E., and Podos, J. (2010). Female mate choice based upon male motor performance. Anim. Behav. 79, 771-778. doi: 10.1016/j.anbehav.2010.01.009

Catchpole, C. K., and Slater, P. J. B. (2008). Bird Song: Biological Themes and Variations. Cambridge; New York, NY: Cambridge University Press.

Clutton-Brock, T., and Huchard, E. (2013). Social competition and its consequences in female mammals. J. Zool. 289, 151-171. doi: 10.1111/jzo.12023

Csardi, G., and Nepusz, T. (2006). The igraph software package for complex network research. Inter. J. Compl. Syst. 1695, 1-9.

Dahlin, C. R., and Benedict, L. (2014). Angry birds need not apply: a perspective on the flexible form and multifunctionality of avian vocal duets. Ethology 120, 1-10. doi: 10.1111/eth.12182

Di-Rienzo, J., Casanoves, F., Balzarini, M., Gonzalez, L., Tablada, M., and Robledo, C. (2012). Infostat versión 2012. Infostat Group, Facultad de Ciencias Agropecuarias, Universidad Nacioal de Córdoba, Argentina.

Dowling, J., and Webster, M. S. (2015). An experimental test of duet function in a fairy-wren (Malurus) with moderate cuckoldry rates. Behav. Ecol. 27, 228-236. doi: 10.1093/beheco/arv144

Dowling, J. L., and Webster, M. S. (2013). The form and function of duets and choruses in Red-backed Fairy-wrens. Emu 113, 282-293. doi: 10.1071/MU12082

Emlen, S. T., and Oring, L. W. (1977). Ecology, sexual selection, and the evolution of mating systems. Science 197, 215-223. doi: 10.1126/science.327542

Griffiths, R., Double, M. C., Orr, K., and Dawson, R. J. (1998). A DNA test to sex most birds. Mol. Ecol. 7, 1071-1075. doi: 10.1046/j.1365-294x.1998.00389.x

Hahn, A. H., Krysler, A., and Sturdy, C. B. (2013). Female song in blackcapped chickadees (Poecile atricapillus): acoustic song features that contain individual identity information and sex differences. Behav. Process 98, 98-105. doi: 10.1016/j.beproc.2013.05.006

Hall, M. L. (2004). A review of hypotheses for the functions of avian duetting. Behav. Ecol. Sociobiol. 55, 415-430. doi: 10.1007/s00265-003-0741-x

Hall, M. L. (2006). Convergent vocal strategies of males and females are consistent with a cooperative function of duetting in Australian magpie-larks. Behaviour 143, 425-450. doi: 10.1163/156853906776240623
Integrative and Comparative Biology, Society for the Study of Evolution, University of Maryland Baltimore Country Graduate Student Association, and Wilson Ornithological Society. KJO was supported by a GAANN Fellowship during initial data collection. KEO was supported by NSF DEB-1119506, and several undergraduate field assistants were supported on REU supplements to that grant. DL was supported by a Discovery Grant from the Natural Sciences and Engineering Research Council of Canada (RGPIN-2015-06553).

\section{SUPPLEMENTARY MATERIAL}

The Supplementary Material for this article can be found online at: http://journal.frontiersin.org/article/10.3389/fevo. 2016.00014
Illes, A. E., and Yunes-Jimenez, L. (2009). A female songbird out-sings male conspecifics during simulated territorial intrusions. Proc. Biol. Sci. 276, 981-986. doi: 10.1098/rspb.2008.1445

Jaramillo, A., and Burke, P. (1999). New World Blackbirds: The Icterids. Princeton, NJ: Princeton University Press.

Jolliffe, I. T. (2002). Principal Component Analysis, 2nd Edn. New York, NY: Springer.

Langmore, N. E. (1998). Functions of duet and solo songs of female birds. Trends Ecol. Evol. 13, 136-140. doi: 10.1016/S0169-5347(97)01241-X

Lebas, N. R. (2006). Female finery is not for males. Trends Ecol. Evol. 21, 170-173. doi: 10.1016/j.tree.2006.01.007

Logue, D. M., Droessler, E. E., Roscoe, D. W., Vokey, J. R., Rendall, D., and Kunimoto, R. M. (2007). Sexually antithetical song structure in a duet singing wren. Behaviour 144, 331-350. doi: 10.1163/1568539077804 25749

Logue, D. M., and Gammon, D. E. (2004). Duet song and sex roles during territory defence in a tropical bird, the black-bellied wren, Thryothorus fasciatoventris. Anim. Behav. 68, 721-731. doi: 10.1016/j.anbehav.2003.10.026

Mennill, D. J., Vehrencamp, S. L., and Yasukawa, K. (2005). Sex differences in singing and duetting behavior of neotropical rufousand-white wrens (Thryothorus rufalbus). Auk 122, 175-186. doi: 10.1642/0004-8038(2005)122[0175:SDISAD]2.0.CO;2

Molles, L. E., Hudson, J. D., and Waas, J. R. (2006). The mechanics of duetting in a New Zealand endemic, the kokako (Callaeas cinerea wilsoni): song at a snail's pace. Ethology 112, 424-436. doi: 10.1111/j.1439-0310.2005. 01168.x

Morton, E. S. (1996). "A comparison of vocal behavior among tropical and temperate passerine birds," in Ecology and Evolution of Acoustic Communication in Birds, eds D. E. Kroodsma and E. H. Miller (Ithaca, NY: Cornell University Press), 258-268.

Odom, K. J., Hall, M. L., Riebel, K., Omland, K. E., and Langmore, N. E. (2014). Female song is widespread and ancestral in songbirds. Nat. commun. 5, 3379. doi: $10.1038 /$ ncomms4379

Podos, J. (1997). A performance constraint on the evolution of trilled vocalization in a songbird family (Passeriformes: Emberizidae). Evolution, 537-551. doi: $10.2307 / 2411126$

Podos, J., and Nowicki, S. (2004). Performance limits on birdsong. Nat. Mus. 318-342. doi: 10.1016/B978-012473070-0/50014-1

Price, J. J., Yunes-Jimenez, L., Osorio-Beristain, M., Omland, K. E., and Murphy, T. G. (2008). Sex-role reversal in song? Females sing more frequently than males in the Streak-backed Oriole. Condor 110, 387-392. doi: 10.1525/cond.2008.8430

Raffaele, H. A., House, C. J., and Wiessinger, J. (1989). A Guide to the Birds of Puerto Rico and the Virgin Islands. Princeton, NJ: Princeton University Press Princeton.

Riebel, K., Hall, M. L., and Langmore, N. E. (2005). Female songbirds still struggling to be heard. Trends Ecol. Evol. 20, 419-420. doi: 10.1016/j.tree.2005.04.024 
Rogers, A. C. (2005). Male and female song structure and singing behaviour in the duetting eastern whipbird, Psophodes olivaceus. Aust. J. Zool. 53, 157-166. doi: 10.1071/ZO04083

Sasahara, K., Cody, M. L., Cohen, D., and Taylor, C. E. (2012). Structural design principles of complex bird songs: a network-based approach. PLoS ONE 7:e44436. doi: 10.1371/journal.pone.0044436

Skutch, A. F. (1996). Orioles, Blackbirds, and Their Kin: A Natural History. Tucson, AZ: University of Arizona Press.

Sonnenschein, E., and Reyer, H. U. (1983). Mate-guarding and other functions of antiphonal duets in the slate-coloured boubou (Laniarius funebris). $Z$. Tierpsychol. 63, 112-140. doi: 10.1111/j.1439-0310.1983.tb00083.x

Stutchbury, B. J., and Morton, E. S. (2001). Behavioral Ecology of Tropical Birds. San Diego, CA: Academic Press.

R Core Team (2015). R: A Language and Environment for Statistical Computing [Internet]. Vienna, Austria: R Foundation for Statistical Computing; 2013. Available online at: http://www.r-project.org

Tobias, J. A., Montgomerie, R., and Lyon, B. E. (2012). The evolution of female ornaments and weaponry: social selection, sexual selection and ecological competition. Philos. Trans. R. Soc. B 367, 2274-2293. doi: $10.1098 /$ rstb. 2011.0280

Tobias, J. A., and Seddon, N. (2009). Signal jamming mediates sexual conflict in a duetting bird. Curr. Biol. 19, 577-582. doi: 10.1016/j.cub.2009.02.036
Topp, S. M., and Mennill, D. J. (2008). Seasonal variation in the duetting behaviour of rufous-and-white wrens (Thryothorus rufalbus). Behav. Ecol. Sociobiol. 62, 1107-1117. doi: 10.1007/s00265-0070538-4

West-Eberhard, M. J. (1983). Sexual selection, social competition, and speciation. Q. Rev. Biol. 58, 155-183. doi: 10.1086/413215

Zollinger, S. A., Podos, J., Nemeth, E., Goller, F., and Brumm, H. (2012). On the relationship between, and measurement of, amplitude and frequency in birdsong. Anim. Behav. 84, e1-e9. doi: 10.1016/j.anbehav.2012. 04.026

Conflict of Interest Statement: The authors declare that the research was conducted in the absence of any commercial or financial relationships that could be construed as a potential conflict of interest.

Copyright (c) 2016 Odom, Omland, McCaffrey, Monroe, Christhilf, Roberts and Logue. This is an open-access article distributed under the terms of the Creative Commons Attribution License (CC BY). The use, distribution or reproduction in other forums is permitted, provided the original author(s) or licensor are credited and that the original publication in this journal is cited, in accordance with accepted academic practice. No use, distribution or reproduction is permitted which does not comply with these terms. 